Editorial for Géotechnique Volume 70 Issue 11, November 2020

\title{
Geotechnical Design for Offshore Wind Turbine Monopiles
}

Offshore wind energy is a central element of the world-wide vision for green energy. As of 2020 the UK has more than 2500 offshore wind turbines, either operational or in construction; many more will be installed over the coming decades. Across Europe and the rest of the world there are similarly ambitious plans to expand offshore wind, creating a sustainable long-term renewable energy supply to combat climate change. Current and next generation wind farms are the power stations of the future, generating multi-GWs of electricity for domestic and commercial use. An offshore wind farm now typically consists of 100 or more $9 \mathrm{MW}$ turbines, across sites covering many hundreds of square kilometres, with a range of environmental and geological conditions. Driving down capital costs of installation is central to executing the longer-term vision, requiring advanced engineering to address mass production design coupled with location-specific optimisation.

An offshore wind turbine comprises the rotor-nacelle-tower assembly located above the ocean surface on a stable platform, supported by the sub-structure and foundation. In the most commonly deployed system, the tower is fixed, via a transition piece, onto a monopile foundation. Monopiles are large diameter steel tubes, usually impact driven into the seafloor; typical current dimensions are $8 \mathrm{~m}$ to $10 \mathrm{~m}$ in diameter, $30 \mathrm{~m}$ to $40 \mathrm{~m}$ long and weighing up to 1000 tonnes. Next generation monopiles will be even larger. Optimisation of the foundation design is critical to wind farm economics and long-term wind turbine performance; for example the foundation, including installation, accounts for approximately $20 \%$ of the installed capital cost. Fabrication of monopiles is relatively straightforward, with an established supply chain, which incentivises their continued use into the future for larger turbines and in deeper water.

Field measurements from early monopile-supported offshore wind turbines identified higher natural frequencies than anticipated on the basis of the design calculations, indicating that the overall turbine support system was significantly stiffer than expected. The foundation design was identified as a key source of this discrepancy, motivating the industry-led PISA (Pile-Soil Analysis) Project, administered through the Carbon Trust's Offshore Wind Accelerator. The industry consortium for the project was led by $\emptyset$ rsted, and involved a further 10 partners including several key European wind farm developers, who, combined, are responsible for a majority of European installed offshore wind capacity. The scientific work was undertaken by an Academic Work Group led by the University of Oxford, working with Imperial College London and University College Dublin. The close interaction between industry and academic teams focused the work on practical engineering design methods targeted at soil profiles relevant to UK and European offshore wind farm sites, to enable rapid application of the research outcomes in design by the industry partners.

The key research achievement from the project was the development of new methods to capture accurately the detailed monopile soil-structure interaction behaviour, facilitating site-specific and turbine support structure-specific optimisation. These developments were achieved by a wide range of connected activities: (a) site investigation and soil characterisation (Zdravković et al., 2020a), (b) numerical modelling, employing sophisticated three-dimensional finite element analysis (Zdravković et al., 2020b; Taborda et al., 2020), (c) theoretical developments including simplified design procedures (Byrne et al., 2020b; Burd et al., 2020b, 2020c), and (d) a comprehensive medium scale field pile testing campaign to validate the new design methods (Burd et al., 2020a; Byrne et al., 2020a; McAdam et al., 2020). 
The basis for the new design methods comes from state-of-the-art 3D finite element (FE) analyses of laterally loaded piles under monotonic loading typical for offshore wind foundations. Analyses were performed for both clay and sand soils, representative of North Sea wind farm sites, following their advanced characterisation through laboratory and field investigations. The new design approach which is based on a one dimensional (1D) simplified finite element model of the embedded monopile - draws on existing techniques (e.g. the $p$-y approach) but with a distinctly improved formulation for the soil reaction responses. The 1D model is developed, calibrated and validated by means of 3D FE results. The modelling process demonstrates that for long piles a (modified) $p-y$ approach may be suitable for design, whereas for large diameter, relatively short monopiles the $p-y$ approach alone cannot predict the response reliably. Three additional soil reaction components are identified, accounting for base shear and moment, and a distributed moment along the pile. If these are used to extend the $p-y$ approach, the pile response can be accurately computed.

A campaign of 28 medium scale field pile tests, with diameters $0.273 \mathrm{~m}, 0.762 \mathrm{~m}$ and $2.0 \mathrm{~m}$, was designed, procured, constructed and executed to test the new design methods (Burd et al., 2020a; Byrne et al., 2020a; McAdam et al., 2020). The tests were carefully planned, based on 3D FE analyses calibrated to the test site soil profiles through advanced laboratory and field characterisation (Zdravković et al., 2020a), and covering a range of loading conditions appropriate to offshore wind turbines. The numerous instruments deployed for the testing, including fibre optic strain measurements, provided high quality high resolution pile test data. The field tests validated the 3D FE models, providing high confidence that the developed computational approach can be used to predict the performance of full-scale large diameter monopiles (Zdravković et al., 2020b; Taborda et al., 2020). Socotec UK Ltd was contracted to perform the medium scale pile testing activities.

The 1D PISA design model, which is an extension of the $p-y$ approach in which the additional soil reaction curves are applied (Byrne et al., 2020b; Burd et al., 2020b, 2020c), is regarded as a key advance. The model is ideally suited to computational requirements for monopile optimisation and offshore wind farm design. Two alternative approaches are proposed to calibrate the soil reaction curves employed in the model. The first approach is to apply a 'rule based method', using lookup tables to derive appropriate inputs for the model, determined by site-specific soil strength and stiffness parameters. This is akin to currently codified design procedures. The second, more detailed, approach involves the application of bespoke 3D finite element modelling to calibrate site-specific soil reaction curves. This site-specific design approach offers a significant step forward in the optimisation of monopile design. These design approaches facilitate simplified calculations that have the fidelity of more complex 3D finite element calculations, but computed in a fraction of the time, covering a wide range of design conditions.

The PISA design model can be applied to a range of common soil types found in the offshore environment. It is demonstrated firstly for homogeneous clay and sand soils (Byrne et al., 2020b; Burd et al., 2020b) and then further developed to account for typically-encountered layered soil profiles (Burd et al., 2020c). In the form presented in the current issue the model is applicable to monotonic loading only, though future extensions to cyclic loading are planned. The procedures are relevant to concept design or for more detailed design, and can be adapted depending on the amount of site investigation data available to the design team. Importantly the procedures allow the design calculation to address each individual turbine location, accounting for the wide range of geological profiles found across very large wind farm sites. The procedures specifically address the computational requirements for the engineering design team, where many load cases and design scenarios must be considered in a short period of time. The general techniques can also be applied to other foundation types and more generally to a wider range of design problems. 
To facilitate dissemination of the outputs of the PISA project all nine papers in this issue have been made available in Open Access. It is hoped that the papers will make a significant contribution to the development of sustainable energy sources.

Byron Byrne, University of Oxford

$\emptyset$ rsted / Royal Academy of Engineering Research Chair in Advanced Geotechnical Design

Principal Investigator for the PISA Project 


\section{$\underline{\text { References, ordered in sequence }}$}

Zdravković, L., Jardine, R.J., Taborda D.M.G., Abadias, D., Burd, H.J., Byrne, B.W., Gavin, K.G, Houlsby, G.T., Igoe, D.J.P., Liu, T, Martin, C.M., McAdam, R.A., Muir Wood, A., Potts, D.M., Skov Gretlund, J. \& Ushev, E. (2020a). Ground characterisation for PISA pile testing and analysis. Géotechnique, https://doi.org/10.1680/jgeot.18.PISA.001

Burd, H.J., Beuckelaers, W.J.A.P., Byrne, B.W., Gavin, K.G, Houlsby, G.T., Igoe, D.J.P., Jardine, R.J., Martin, C.M., McAdam, R.A., Muir Wood, A., Potts, D.M., Skov Gretlund, J., Taborda, D.M.G. \& Zdravković, L. (2020a). New data analysis methods for instrumented medium scale monopile field tests. Géotechnique, https://doi.org/10.1680/jgeot.18.PISA.002

Byrne, B.W., McAdam, R.A., Burd, H.J., Beuckelaers, W.J.A.P., Gavin, K.G, Houlsby, G.T., Igoe, D.J.P., Jardine, R.J., Martin, C.M., Muir Wood, A., Potts, D.M., Skov Gretlund, J., Taborda, D.M.G. \& Zdravković, L. (2020a). Monotonic laterally loaded pile testing in a stiff glacial clay till at Cowden. Géotechnique, https://doi.org/10.1680/jgeot.18.PISA.003

McAdam, R.A., Byrne, B.W., Houlsby, G.T., Beuckelaers, W.J.A.P., Burd, H.J., Gavin, K.G, Igoe, D.J.P., Jardine, R.J., Martin, C.M., Muir Wood, A., Potts, D.M., Skov Gretlund, J., Taborda, D.M.G. \& Zdravković, L. (2020). Monotonic laterally loaded pile testing in a dense marine sand at Dunkirk. Géotechnique, https://doi.org/10.1680/jgeot.18.PISA.004

Zdravković, L., Taborda, D.M.G., Potts, D.M., Abadias, D., Burd, H.J., Byrne, B.W., Gavin, K.G, Houlsby, G.T., Jardine, R.J., Martin, C.M., McAdam, R.A. \& Ushev, E. (2020b). Finite element modelling of laterally loaded piles in a stiff glacial clay till at Cowden. Géotechnique, https://doi.org/10.1680/jgeot.18.PISA.005

Taborda, D.M.G., Zdravković, Potts, D.M., Burd, H.J., Byrne, B.W., Gavin, K.G, Houlsby, G.T., Jardine, R.J., Liu, T., Martin, C.M. \& McAdam, R.A. (2020). Finite element modelling of laterally loaded piles in a dense marine sand at Dunkirk. Géotechnique, https://doi.org/10.1680/jgeot.18.PISA.006

Byrne, B.W., Houlsby, G.T., Burd, H.J., Gavin, K.G, Igoe, D.J.P., Jardine, R.J., Martin, C.M., McAdam, R.A., Potts, D.M., Taborda, D.M.G. \& Zdravković, L. (2020b). PISA design model for monopiles for offshore wind turbines: Application to a stiff glacial clay till. Géotechnique, https://doi.org/10.1680/jgeot.18.P.255

Burd, H.J., Taborda, D.M.G., Zdravković, L., Abadie, C.N., Byrne, B.W., Gavin, K.G, Houlsby, G.T., Igoe, D.J.P., Jardine, R.J., Martin, C.M., McAdam, R.A., Pedro, A.M.G. \& Potts, D.M. (2020b). PISA design model for monopiles for offshore wind turbines: Application to a marine sand. Géotechnique, https://doi.org/10.1680/jgeot.18.P.277

Burd, H.J., Abadie, C.N., Byrne, B.W., Houlsby, G.T., Martin, C.M., McAdam, R.A., Jardine, R.J., Pedro, A.M.G., Potts, D.M., Taborda, D.M.G., Zdravković, L \& Pacheco Andrade, M. (2020c) Application of the PISA design model to monopiles embedded in layered soils. Géotechnique, https://doi.org/10.1680/jgeot.20.PISA.009 